\title{
THE STATISTICS OF PREMATURITY
}

\section{A PLEA FOR STANDARDIZATION}

BY

\author{
J. L. HENDERSON, M.D., F.R.C.P. (Ed.)
}

Lecturer, Department of Child Life and Health, University of Edinburgh; Assistant Paediatrician, Simpson Memorial Maternity Pavilion, Royal Infirmary, Edinburgh

A standardized method of presenting statistics on prematurity is the only sure foundation on which to build reliable scientific data regarding this major paediatric problem. Hitherto, it has not been possible to compare the prematurity statistics emanating from maternity hospitals, owing to the lack of a uniform method of statistical analysis. To enable accurate comparisons to be made between various methods of care and treatment it is suggested that the following seven conditions would provide a comparative basis:

(1) A large number of infants.

(2) Accurate weighing at birth.

(3) Strict interpretation of the definition 'liveborn.'

(4) Inclusion of all liveborn infants with congenital malformations.

(5) Ilefinition of the weight range of viable prematurity.

(6) Subdivision of the standard weight range into half-pound weight groups.

(7) Segregation of the infants of booked mothers from those of unbooked mothers.

1. A large number of infants. Conclusions which are statistically significant can be drawn only from a large series of consecutive cases. There should be several hundred, preferably 500 or more. The importance of this becomes more apparent when the need for subdividing premature infants into several standard weight groups is appreciated, since, as a result of such subdivision, the proportion of infants in the lighter weight groups is small, and figures relating to small numbers are statistically insignificant. Table I shows the number and the percentage of infants in each half-pound weight group in each of six consecutive years, and in the aggregate, at the Simpson Maternity Hospital, Edinburgh. It is apparent how much more widely the figures vary from year to year in the lighter weight groups, where there are relatively few cases, than in the heavier weight groups where the numbers are much larger. The danger of drawing false conclusions from small series of cases has recently been emphasized by Crosse (1945).

2. Accurate weighing at birth. Sensitive, accurate weighing machines are essential for recording the birth-weight of premature infants, if accurate definition of the standard weight range and accurate allocations into standard subdivisions are to be attained. The birth-weights of infants born in

TABLE I

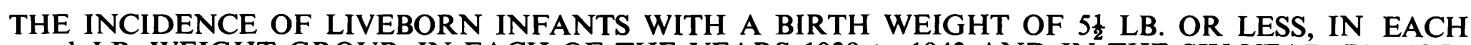
$\frac{1}{2}$ LB. WEIGHT GROUP, IN EACH OF THE YEARS 1938 to 1943 AND IN THE SIX-YEAR PERIOD, AT THE SIMPSON MATERNITY HOSPITAL, EDINBURGH.

\begin{tabular}{|c|c|c|c|c|c|c|c|c|c|c|c|c|c|c|c|c|c|c|c|}
\hline \multirow{3}{*}{ Year } & \multicolumn{18}{|c|}{ Weight group in pounds } & \multirow{3}{*}{$\begin{array}{l}\text { Total } \\
\text { no. of } \\
\text { infants }\end{array}$} \\
\hline & \multicolumn{2}{|c|}{$5 \frac{1}{2}-5$ incl. } & \multicolumn{2}{|c|}{$4.15 \frac{3}{4}-4 \frac{1}{2}$} & \multicolumn{2}{|c|}{$4.7 \frac{3}{4}-4$} & \multicolumn{2}{|c|}{$3.15 \frac{3}{4}-3 \frac{1}{2}$} & \multicolumn{2}{|c|}{$3.7 \frac{3}{4}-3$} & \multicolumn{2}{|c|}{$2.15 \frac{3}{4}-2 \frac{1}{2}$} & \multicolumn{2}{|c|}{$2.7 \frac{3}{4}-2$} & \multicolumn{2}{|c|}{$1.15 \frac{3}{4}-1 \frac{1}{2}$} & \multicolumn{2}{|c|}{$1.7 \frac{3}{4}-1$} & \\
\hline & No. & $\%$ & No. & $\%$ & No. & $\%$ & No. & $\%$ & No. & $\%$ & No. & $\%$ & No. & $\%$ & No. & $\%$ & No. & $\%$ & \\
\hline $\begin{array}{l}1939 \\
1940 \\
1941 \\
1942 \\
1943 \\
1944\end{array}$ & $\begin{array}{r}73 \\
86 \\
111 \\
92 \\
92 \\
96\end{array}$ & $\begin{array}{l}34.9 \\
36.9 \\
41.7 \\
35.7 \\
34.7 \\
36.0\end{array}$ & $\begin{array}{l}39 \\
47 \\
46 \\
59 \\
60 \\
45\end{array}$ & $\begin{array}{l}18 \cdot 7 \\
20 \cdot 2 \\
17 \cdot 3 \\
22 \cdot 5 \\
22 \cdot 6 \\
16 \cdot 8\end{array}$ & $\begin{array}{l}28 \\
35 \\
39 \\
38 \\
41 \\
45\end{array}$ & $\begin{array}{l}13 \cdot 4 \\
15 \cdot 0 \\
14 \cdot 3 \\
14 \cdot 7 \\
15 \cdot 5 \\
16 \cdot 8\end{array}$ & $\begin{array}{l}21 \\
28 \\
19 \\
23 \\
24 \\
28\end{array}$ & $\begin{array}{r}10.0 \\
12.0 \\
7.1 \\
8.9 \\
9.0 \\
10.5\end{array}$ & $\begin{array}{l}18 \\
16 \\
14 \\
17 \\
19 \\
24\end{array}$ & $\begin{array}{l}8 \cdot 6 \\
6 \cdot 9 \\
5 \cdot 3 \\
6 \cdot 6 \\
7 \cdot 2 \\
9 \cdot 0\end{array}$ & $\begin{array}{l}12 \\
10 \\
16 \\
15 \\
12 \\
14\end{array}$ & $\begin{array}{l}5 \cdot 7 \\
4 \cdot 3 \\
6 \cdot 0 \\
5 \cdot 8 \\
4 \cdot 5 \\
5 \cdot 2\end{array}$ & $\begin{array}{r}10 \\
7 \\
14 \\
11 \\
10 \\
5\end{array}$ & $\begin{array}{l}4 \cdot 8 \\
3 \cdot 0 \\
5 \cdot 3 \\
4 \cdot 2 \\
3 \cdot 8 \\
1 \cdot 9\end{array}$ & $\begin{array}{l}8 \\
4 \\
8 \\
3 \\
1 \\
9\end{array}$ & $\begin{array}{l}3.9 \\
1.7 \\
3.0 \\
1.2 \\
0.4 \\
3.4\end{array}$ & $\begin{array}{l}0 \\
0 \\
0 \\
1 \\
6 \\
1\end{array}$ & $\begin{array}{r}0 \\
0 \\
0 \\
0 \cdot 4 \\
2 \cdot 3 \\
0.4\end{array}$ & $\begin{array}{l}209 \\
233 \\
267 \\
259 \\
265 \\
267\end{array}$ \\
\hline $\begin{array}{r}1939- \\
1944\end{array}$ & 550 & $36 \cdot 7$ & 296 & $19 \cdot 7$ & 226 & $15 \cdot 0$ & 143 & $9 \cdot 6$ & 108 & $7 \cdot 2$ & 79 & $5 \cdot 3$ & 57 & $3 \cdot 8$ & 33 & $2 \cdot 2$ & 8 & 0.5 & 1,500 \\
\hline
\end{tabular}


large maternity hospitals, only, can be accepted as reliable. In many small maternity hospitals and in most nursing homes various types of inaccurate and unreliable weighing machines are employed.

3. Strict interpretation of the definition ' liveborn.' The necessity for rigid interpretation of the definition of a liveborn infant requires emphasis, because it is a great temptation to classify infants who die within a few minutes or hours of birth as stillbirths, and thus improve the neonatal mortality figures. It is a common practice in the United States and elsewhere (Barnes and Willson, 1942) to exclude from the category of liveborn infants all those who die within twenty-four hours of birth. Since the mortality in premature infants, particularly in the lighter weight groups, is concentrated in the first day of life, strict interpretation of the definition of a liveborn premature infant, as defined by the American Academy of Pediatrics (1935), is a statistical necessity. The definition reads: 'A premature infant is one who weighs $2,500 \mathrm{~g}$. or less at birth (not on admission) regardless of the period of gestation. All liveborn premature infants should be included, evidence of life being heart-beating or breathing.'

In the seven years period 1938-44 at the Simpson Maternity Hospital, Edinburgh, 489 infants who weighed $5 \frac{1}{2} \mathrm{lb}$. or less at birth died in the hospital; 48.9 per cent. died within 24 hours of birth and 24.1 per cent. within 6 hours of birth. These figures prove the absolute necessity for strict interpretation of the definition 'liveborn' if prematurity statistics are to have any scientific value.

4. The inclusion of all liveborn infants with congenital malformations. All liveborn infants with congenital malformations should be classified as livebirths, even if the malformation is regarded as being incompatible with survival. This point requires emphasis in the interests of statistical accuracy, because it is a common practice to eliminate liveborn infants with congenital malformations judged to be incompatible with survival from the category of livebirths (Barnes and Willson, 1942). Since the prognosis regarding survival depends to a considerable extent on personal opinions, it is highly desirable that this factor should be eliminated by classifying all liveborn infants with congenital malformations, however severe, as livebirths.

5. Definition of the weight range of viable prematurity. A standardized weight range of viable prematurity would provide a common statistical basis. This is a fundamental necessity where figures embracing all premature infants, without division into subgroups, are given; though it is not so essential where the subdivision of premature infants into numerous standard weight groups is practised.

The MAXIMUM WeIGHT STANDARD. At the present time this is the only universal weight standard of prematurity. The definition reads-" A premature infant is one who weighs $5 \frac{1}{2} \mathrm{lb}$. $(2,500 \mathrm{~g}$.) or less, at birth, regardless of the period of gestation.' This standard was first advocated as a suitable international standard by Ylppö in 1919, and it was soon generally adopted on the European Continent. It was officially recognized by the American Academy of Pediatrics in 1935 (Hess and Lundeen, 1941), although it had previously been adopted by numerous American workers, and it was officially recognized in Great Britain in 1938 (Brit. med. J., 1938). The adoption of this universal upper-weight standard of prematurity has proved of great statistical value. Paediatricians have found it much more satisfactory than the estimated incomplete period of gestation standard, which formerly had been the standard of prematurity in general use.

The old definition has three main disadvantages: (1) The frequent uncertainty regarding the date of onset of the last menstrual period. (2) The frequency with which infants estimated to be premature weigh 6 to $7 \mathrm{lb}$. or more. (3) The frequency with which infants estimated to be mature weigh $5 \frac{1}{2} \mathrm{lb}$. or less.

The new definition has two main advantages: (1) The weight of $5 \frac{1}{2} \mathrm{lb}$. constitutes an appropriate dividing line between infants who are clinically mature and those who are clinically immature. Those who weigh more do not require special nursing care, whereas those who weigh less do require it. (2) Exact correspondence between the avoirdupois and metric systems in round figures does not occur at any other point in the neighbourhood of 5 to $6 \mathrm{lb}$. This is the principal reason for the adoption of the weight standard of precisely $5 \frac{1}{2} \mathrm{lb}$. $(2,500 \mathrm{~g}$.).

A MINIMUM WEIGHT STANDARD. The adoption of a universal minimum weight standard of prematurity is highly desirable. Numerous workers have recognized this fact and various standards have been suggested and used by them, but no official recommendation regarding a minimum weight standard has yet been made. Some workers have used a standard of viability of $1,000 \mathrm{~g}$. $(2 \mathrm{lb}$. $3 \cdot 2 \mathrm{oz}$. whilst others prefer a standard of $1,500 \mathrm{~g}$. (3 lb. 4.8 oz.). Various standards between these two extremes have also been suggested. A minimum weight standard of $2 \frac{3}{4} \mathrm{lb}$. $(1,250 \mathrm{~g}$.) was recently suggested by myself (Henderson, 1945) as being the most suitable lower weight standard of viable prematurity. The figure of $2 \frac{3}{4} \mathrm{lb}$. was shown to correspond approximately to an estimated gestation period of 28 weeks, the generally accepted age at which the foetus is presumed to become viable. The problem of attempting to find the average weight of infants, at the twenty-eighth week of gestation, was approached by analysing the relationship between the birth-weight and the estimated period of gestation in 1,041 liveborn single premature infants born in the Simpson Maternity Hospital in the six-year period 1938 to 1943. To endeavour to achieve a true relationship twin infants totalling 252 were excluded from the whole series of 1,293 liveborn infants who weighed $5 \frac{1}{2} \mathrm{lb}$. or less at birth, because twin infants weigh less than single infants of the same foetal age. Stillborn and deadborn premature infants were also 
excluded from the calculation, because the relationship between the weight and the foetal age is very variable in these circumstances owing to the frequency of gross congenital defects and intrauterine death.

In the series of 1,041 single liveborn premature infants there were 44 infants in the 3 to $2 \frac{1}{2} \mathrm{lb}$. weight group with an average gestation period of 28.9 weeks, and 34 infants in the $2 \frac{1}{2}$ to $2 \mathrm{lb}$. weight group with an average gestation period of $27 \cdot 7$ weeks. These figures seemed to point to a lower weight limit of viability of between $2 \frac{1}{2} \mathrm{lb}$. and $2 \mathrm{lb}$., but, as pointed out at the time, there is an important reason why the average weight of infants of 28 weeks gestation cannot be accurately calculated from hospital records. It is dependent on the general practice of regarding many infants who have a gestation period of 26 to 28 weeks as viable, and recording them as having an estimated gestation period of over 28 weeks to enable the mother to receive her maternity benefit. Such a practice seems quite justifiable, because the duration of gestation is only an approximate estimation and it is certainly right that the mother should receive the benefit of any doubt in borderline cases. From the statistical point of view, however, this practice vitiates the figures relating to the lower weight groups of premature infants, as a considerable number of previable infants are notified as viable. It was concluded, therefore, that the figure of 28.9 weeks exceeded the actual period of gestation in the 3 to $2 \frac{1}{2} \mathrm{lb}$. group, and that the average weight of infants of 28 weeks' gestation probably lies somewhere between $3 \mathrm{lb}$. and $2 \frac{1}{2} \mathrm{lb}$.

It appeared from the above evidence that the most suitable universal minimum weight standard of viability which can be based on the generally accepted ' 28 weeks' gestation period' standard of viability is the weight of $2 \frac{3}{4} \mathrm{lb}$. $(1,250 \mathrm{~g}$.). There are three good reasons why a birth-weight of $2 \frac{3}{4} \mathrm{lb}$. should be accepted as the most suitable minimum weight standard of viable prematurity. They are: (1) The average weight of infants of 28 weeks' gestation appear to lie between 3 and $2 \frac{1}{2} \mathrm{lb}$. (2) The weight of $2 \frac{3}{4} \mathrm{lb}$. avoirdupois corresponds exactly with the weight of $1 \frac{1}{4} \mathrm{~kg}$. $(1,250 \mathrm{~g}$.) in the metric system, a correspondence in round figures which is unattainable at any other point in the neighbourhood of 3 to $2 \frac{1}{2} \mathrm{lb}$. (3) The minimum figure of $2 \frac{3}{4} \mathrm{lb}$. (1 $1 \frac{1}{4} \mathrm{~kg}$.) is exactly half of the maximum figure

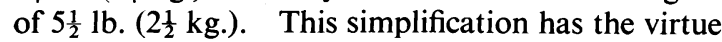
of making the minimum standard easy to remember, as the maximum standard is now well known and in general use.

LIVEBORN PRE-VIABLE INFANTS. Official adoption of the proposed minimum weight standard of viable prematurity of $2 \frac{3}{4} \mathrm{lb}$. would necessitate the provision of a separate category for liveborn infants with a birth-weight of less than $2 \frac{3}{4} \mathrm{lb}$. The term 'pre-viable' would suitably describe this category. Where prematurity figures are considered as a whole it seems desirable that this group of extremely premature infants should be placed in a separate category, because their chances of survival are remote, and it seems both unjustifiable and scientifically unsound to include these infants, who practically speaking are non-viable, in the same category as infants who have a reasonable chance of survival. The recognition of such a category along with the proposed minimum weight standard would encourage obstetricians and registrars in maternity hospitals to be more forthright, and to present figures more in accordance with the facts, than is often the case to-day. At present, there is a reluctance to include extremely premature liveborn infants which do not survive in the general prematurity figures, and an inclination to classify them as abortions. This practice is quite understandable, but it is highly to be deprecated on statistical grounds, and manifestly unfair to those maternity units in which an honest attempt is made to be accurate by including all fatalities among liveborn premature infants, however small, as neonatal deaths.

A total of 118 liveborn infants with a birth weight of less than the proposed minimum standard of viability of $2 \frac{3}{4} \mathrm{lb}$. were born in the Simpson Maternity Hospital, Edinburgh, in the six-year period 1938 to 1943 . The total of liveborn infants with a birth-weight of $5 \frac{1}{2}$ to $2 \frac{3}{4} \mathrm{lb}$. inclusive born in the same period was 1,286. Thus, of 1,404 liveborn infants with a birth-weight of $5 \frac{1}{2} \mathrm{lb}$. or less, $91.6 \mathrm{per}$ cent. would, according to the proposed standards, be classified as premature infants (birth-weight $5 \frac{1}{2}$ to $2 \frac{3}{4} \mathrm{lb}$. inclusive), and 8.4 per cent. would be classified as pre-viable infants (birth-weight less than $2 \frac{3}{4} \mathrm{lb}$.). Only 4 of the 118 ' pre-viable' infants survived. This is a poor survival-rate and better figures are attainable (Cross, 1945). Nevertheless, even in the most ideal circumstances, the death-rate in infants with a birth-weight of less than $3 \frac{3}{4} \mathrm{lb}$. will always remain very high.

WEIGHT STANDARDS OF PREMATURITY AND STILLBIRTH ClASSIFICATION. Stillborn and deadborn premature infants should also be defined as those infants with a birth-weight between $5 \frac{1}{2} \mathrm{lb}$. and $3 \frac{3}{4} \mathrm{lb}$. inclusive. A pre-viable category is unnecessary in the case of stillborn infants, as those with a birthweight of less than $2 \frac{3}{4} \mathrm{lb}$. are, of course, classified as abortions.

The substitution of a minimum weight standard of $2 \frac{3}{4} \mathrm{lb}$. for the customary standard of an estimated gestation period of 28 weeks, would reduce considerably the proportion of premature stillborn infants falling into the category of viable stillborn infants, and increase correspondingly the proportion falling into the category of abortions. The effect of the change of definition in the six-year period 1938 to 1943 at the Simpson Maternity Hospital was as follows: There were 520 stillborn infants which weighed $5 \frac{1}{2} \mathrm{lb}$. or less and which were estimated to have a gestation period of 28 weeks or more (i.e. premature by current standards); 139 (27 per cent.) of these weighed less than $2 \frac{3}{4} \mathrm{lb}$. and would be classified as abortions by the $5 \frac{1}{2}$ to $2 \frac{3}{4}$ lb. standard of viable prematurity. Thus a 
much larger proportion of stillborn infants than of liveborn infants would be eliminated from the category of viable prematurity if the $5 \frac{1}{2}$ to $2 \frac{3}{4} \mathrm{lb}$. standard were to supersede the $5 \frac{1}{2} \mathrm{lb}$. to 28 weeks' standard, and would henceforth be regarded as abortions. The great difference in the proportion of liveborn and stillborn premature infants who would be classified as pre-viable, instead of viable, is explained by the fact that the average weight of stillborn infants is considerably less than the average weight of liveborn infants at a corresponding period of gestation. The principal causes of the lower average weight of stillborn infants are the common occurrence of gross congenital malformations, such as anencephaly, and of intra-uterine death.

The considerable reduction in the number of premature stillborn infants which would follow the adoption of the $2 \frac{3}{4} \mathrm{lb}$. standard of viability would appear to be desirable, because a large proportion of the foetuses which would fall into the pre-viable (abortion) group would show either gross congenital malformations or maceration following intra-uterine death, and should not under any circumstances be classified as viable. In the series of 520 premature stillborn infants previously mentioned, 29 per cent. of the foetuses, which the proposed minimum standard would eliminate from the category of viable prematurity, showed gross congenital malformations, principally anencephaly. Accurate figures relating to intra-uterine death cannot be given, but at least 20 per cent. of those eliminated would probably fall into this category.

COMmENT. A strong case for the adoption of an international minimum birth-weight standard of prematurity would appear to emerge from the foregoing evidence. There is nothing new in the conception of a standard of viability. The standard in general use is that of an estimated gestation period of 28 weeks, and it would seem highly desirable on scientific grounds to institute a common denominator for both the maximum and minimum limits of prematurity. As the maximum weight standard of $5 \frac{1}{2} \mathrm{lb}$. $(2,500 \mathrm{~g}$.) has been proved to be a highly desirable reform, it is surely logical to urge the acceptance of a minimum weight standard of viable prematurity to replace the existing standard with which it corresponds.

6. Subdivision of the standard weight range into standard half-pound weight groups. Subdivision of the standard weight range of prematurity $\left(5 \frac{1}{2}\right.$ to $2 \frac{3}{4} \mathrm{lb}$. inclusive) into several standard weight subdivisions is essential for statistical purposes, because the definition embraces premature infants ranging between those who are slightly premature and those who are extremely premature and have just become viable. Further, the proportion of infants of various weights may vary greatly in different series of cases and it is valueless to compare premature infants of widely differing birth-weight.

It is not possible to achieve exact correspondence in round figures of the avoirdupois and metric systems for several subdivisions of the standard weight range. The best that can be achieved is to divide the avoirdupois range of $5 \frac{1}{2}$ to $2 \frac{3}{4} \mathrm{lb}$. into five $\frac{1}{2} \mathrm{lb}$. subdivisions and one $\frac{1}{4} \mathrm{lb}$. subdivision as follows: $5 \frac{1}{2}$ to $5 \mathrm{lb}$. inclusive, $4 \mathrm{lb} .15 \frac{3}{4} \mathrm{oz}$. to $4 \frac{1}{2} \mathrm{lb}$. inclusive, $4 \mathrm{lb}$. $7 \frac{3}{4} \mathrm{oz}$. to $4 \mathrm{lb}$. inclusive, $3 \mathrm{lb}$. $15 \frac{3}{4} \mathrm{oz}$. to $3 \frac{1}{2} \mathrm{lb}$. inclusive, $3 \mathrm{lb}$. $7 \frac{3}{4} \mathrm{oz}$. to $3 \mathrm{lb}$. inclusive, and $2 \mathrm{lb} .15 \frac{3}{4} \mathrm{oz}$. to $2 \mathrm{lb} .12 \mathrm{oz}$. inclusive; and the metric range of 2,500 to $1,250 \mathrm{~g}$. into five $250 \mathrm{~g}$. subdivisions as follows: 2,500 to $2,250 \mathrm{~g}$. inclusive, 2,249 to $2,000 \mathrm{~g}$. inclusive, 1,999 to $1,750 \mathrm{~g}$. inclusive, 1,749 to $1,500 \mathrm{~g}$. inclusive, 1,499 to $1,250 \mathrm{~g}$. inclusive. The five $\frac{1}{2} \mathrm{lb}$. subdivisions do not quite correspond with the five $250 \mathrm{~g}$. subdivisions, as the five $\frac{1}{2} \mathrm{lb}$. groups cover a range of $\frac{1}{4} \mathrm{lb}$. less than the five $250 \mathrm{~g}$. groups.

The varying proportion of viable premature infants in each half-pound weight group from year to year in the Simpson Maternity Hospital series reviewed is shown in Table $I$.

7. Segregation of the infants of booked mothers from those of unbooked mothers. The term ' booked' refers to mothers who arrange early in pregnancy, without recommendation, to have their confinement in hospital; whereas the term 'unbooked' refers to mothers who are admitted to hospital as obstetrical emergencies, or are recommended for confinement in hospital because of illhealth, obstetric or otherwise, in the present or in a previous pregnancy, or because of multiple pregnancy. The separation of these two groups of cases into separate categories is a fundamental statistical necessity, for the prognosis of the infant is much better (in the aggregate) in booked than in unbooked cases. Nevertheless, this point is usually ignored. If the proportion of booked and of unbooked cases was the same in all maternity hospitals it would not be necessary to make this distinction, but such is far from the case. No unbooked cases are admitted to some maternity hospitals, whereas such cases constitute a substantial minority of the total cases admitted to others.

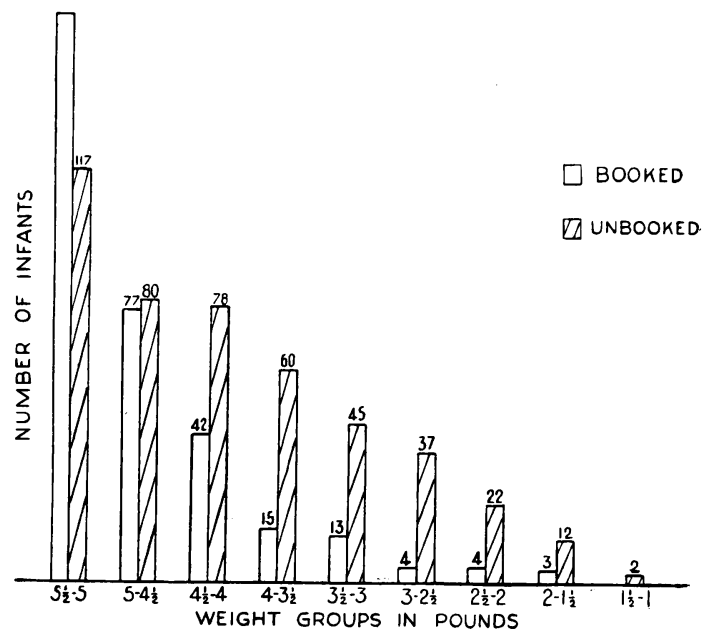

FIG. 1.-The weight incidence in booked and unbooked cases in a consecutive series of 772 premature and pre-viable liveborn infants, born in the three-year period 1942 to 1944 at the Simpson Maternity Hospital, Edinburgh. 
In the three-year period 1942 to 1944 at the Simpson Maternity Hospital, there were 772 liveborn infants (596 single, 166 twins and 10 triplets) with a birth-weight of $5 \frac{1}{2} \mathrm{lb}$. or less; 41 per cent. of them were born of booked mothers and 59 per cent of unbooked mothers. As approximately 80 per cent. of the mothers during this period were booked, the incidence of liveborn infants with a birth-weight of $5 \frac{1}{2} \mathrm{lb}$. or less was 4.7 per cent. in the booked category and 2.71 per cent. in the unbooked category. The number of premature infants in each $\frac{1}{2} \mathrm{lb}$. weight group in this series is shown separately for each of the two categories in

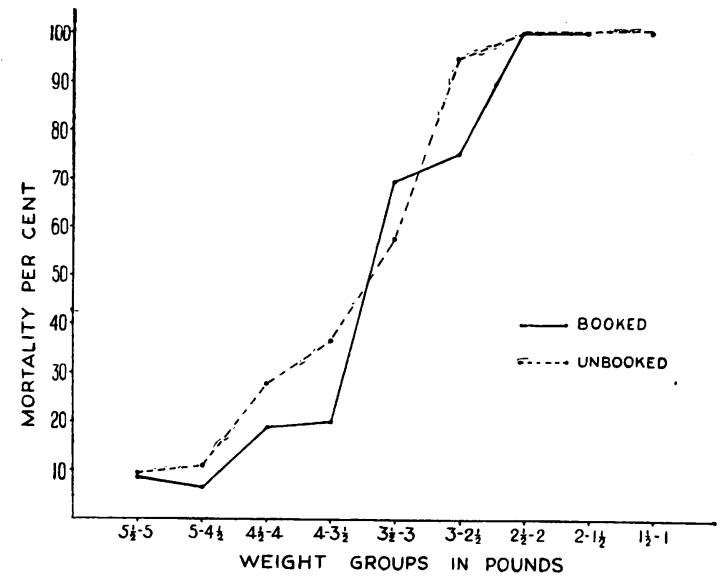

FIG. 2.-The mortality in booked and unbooked cases in each $\frac{1}{2} \mathrm{lb}$. weight group in a consecutive series of 772 premature and pre-viable liveborn infants, born in the three years period 1942 to 1944 at the Simpson Maternity Hospital, Edinburgh.

the diagram in fig. 1. This shows a preponderance of booked cases in the heaviest weight group of $5 \frac{1}{2}$ to $5 \mathrm{lb}$., about an equal number in the two categories in the 5 to $4 \frac{1}{2} \mathrm{lb}$. group and a great preponderance of unbooked cases in all the lighter weight groups. The variability in the proportion of booked and unbooked cases in successive weight groups would be unimportant if the mortality in the two categories was approximately the same in each weight group, but such is far from being the case. The mortality rate for all liveborn premature infants (viable and pre-viable) in the booked cases of the series was 15.4 per cent. and in the unbooked cases it was 35.5 per cent. The frequency of antepartum haemorrhage and of toxaemia in unbooked cases are the principal reasons for the much poorer prognosis in that category. The comparative mortality in each $\frac{1}{2} \mathrm{lb}$. weight group is shown graphically in fig. 2. In each of the three important weight groups 5 to $4 \frac{1}{2} \mathrm{lb}$., $4 \frac{1}{2}$ to $4 \mathrm{lb}$. and 4 to $3 \frac{1}{2} \mathrm{lb}$., together comprising 46 per cent. of the total cases, the unbooked cases showed twice the mortality of the booked cases.

Clearly it is statistically essential to analyse the infants born of booked and of unbooked mothers separately, because (1) there is a great difference in the weight distribution in the two groups, and (2) the prognosis is much poorer in the unbooked cases, particularly in the three important intermediate weight groups ranging from $5 \mathrm{lb}$. to $3 \frac{1}{2} \mathrm{lb}$.

\section{Summary}

The necessity of adopting a standardized method of presenting statistics on prematurity is emphasized.

Seven conditions which would provide a satisfactory statistical basis have been suggested.

\section{REFERENCES}

Barnes, A. C., and Willson, J. R. (1942). J. Amer. med. Ass., 119, 545.

Brit. med. J. (1938). 1, 1011.

Crosse, V. M. (1945). The Premature Baby, London, $136-7$.

Henderson, J. L. (1945). J. Obstet. Gynaec., 52, 29.

Hess, J. H., and Lundeen, E. E. (1941). The Premature Infant, Philadelphia, 1.

Ylppö, A. (1919). Z. Kinderheilk., 24, 1. 